\title{
PHD Defence
}

\section{Contingent Belonging: Second-Generation Latino Canadian Negotiations of Place, Identity, and Nation by Marcos D. Moldes}

This is a news update from School of Communication, Simon Fraser University News Editor: Sibo Chen

Our dear colleague, Marcos D. Moldes, will defend his PHD dissertation on Friday, October 7, 2016 at Harbor Center Room 1600 (9:30 am -12:30 pm). Here is the abstract of his dissertation "Contingent Belonging: Second-Generation Latino Canadian Negotiations of Place, Identity, and Nation".

\begin{abstract}
In an increasingly transnational world where multicultural policies and dual citizenships are facilitated through international conventions, this dissertation provides insight into the identities of the children of the Latino diaspora in Canada and explores how the second- generation (Canadians born in Canada with at least one immigrant parent) expresses a complex sense of belonging not just to Canada but also to their parent's homeland. I argue that their sense of belonging has been misunderstood by academics and Canadian policy makers. Described as being an 'in-between' generation, a series of policy reports published by the Policy Research Initiative of Canada claims they are both a potential risk and potential resource for the state, and thus need to be managed. I argue this fails to recognize how members of the second generation themselves articulate a complex sense of belonging and identity that is negotiated on their own terms. There has been little written about Latina/os in Canada and even less that focuses on the second-generation. Though scholarly fields in the United States like that of Chicano Studies examine questions of diasporic identity in multi-generational Latina/o communities they focus on a uniquely American population.

Drawing on my own diasporic heritage I collected data through four months of autoethnographic (Spry, 2001) and sensory ethnographic fieldwork in Montevideo, Uruguay where my parents grew up and also the site of many annual childhood trips to visit my parents' family. My research involved ethnographic participant observation, interviews and site visits to the Museum of Memory (MuME). The second phase involved interviews of 15 second-generation Latino Canadians ranging in age from 20-35 from four Canadian cities. Like myself this group I was born and raised after the introduction of multicultural policy and the incorporation of multiculturalism into the conceptualization of Canada (Kobayashi, 2008). As an ethnography that encompassed both arriving in Uruguay and returning to Canada, I also observed the practices of "negotiating" my Latino/Canadian identity in each site. Thus
\end{abstract}


the third phase, involved the development of a cooking practice (Counihan, 2010; Antoniou, 2004) which in response to the disorienting period of returning to Canada where I nostalgically longed for Montevideo.

A key component of the study involved developing a voice in academic writing for the sensorial, affective and emotional experience (see: Million, 2013) I found that second-generation subjects like myself experience with their/our sense of belonging and not belonging in the diasporic homeland that is mediated through kinship structures, cultural practices and everyday objects. I define this experience as 'contingent belonging' a concept that recognizes how the identities of the second generation are unstable and dynamic, constantly in a process of being constituted and reconstituted with different meanings in a constantly shifting landscape.

Keywords: Diaspora, Multiculturalism, Belonging, Latino, Latino-Canadian, Ethnography, Cooking, Identity, Autoethnography, Sensory Ethnography, Performance 